\title{
CHEST WALL RIGIDITY ASSOCIATED WITH USE OF SUBARACHNOID SUFENTANIL AND SEDATION WITH FENTANYL
}

Haddad Silveira C., MD; Mateus Marcelino Serzedo P.S., MD; Barbin Zuccolotto E.,MD; Helfenstein E., MD.

\section{Center for Teaching and Training in Anesthesiology (CET-SBA) of the Ribeirão Preto Anesthesiology Clinic (CARP). Ribeirão Preto - SP / Brazil}

\section{European \\ Society of \\ Anaesthesiology}

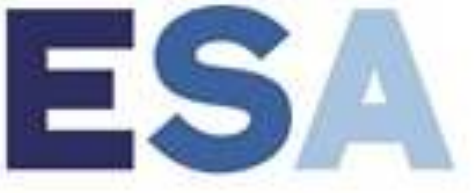

\section{BACKGROUND:}

The use of fentanyl and other opioids is associated with some complications such as chest wall rigidity.

The objective of the present report is to discuss chest wall rigidity after the use of subarachnoid sufentanil associated with sedation with fentanyl in a patient undergoing ureterolithotripsy.

\section{CASE REPORT:}

A 32-year-old woman, P1 according to the ASA classification, $62 \mathrm{~kg}$, subjected to ureterolithotripsy.

Monitored with SpO2, NIBP and ECG (DII and V5).

EV sedation with midazolam $(0.05 \mathrm{mg} / \mathrm{kg})$ and fentanyl $(2 \mathrm{mcg} / \mathrm{kg})$, spinal block using a Quinke $27 \mathrm{G}$ needle between L3-L4, after sterilization and antisepsis with $15 \mathrm{mg}$ of hyperbaric bupivacaine and $7.5 \mathrm{mcg}$ of sufentanil.

After uneventful lumbar puncture, the patient was placed in the lithotomy position.

Soon after the beginning of the procedure, the patient evolved with a progressive drop in oxygen saturation, decreased respiratory rate, and increased respiratory range.

Her chest wall became rigid and the ventilation movements ceased associated with lowering of consciousness level.

Ventilatory support was initiated with a bag valve mask, however the procedure was troublesome and tracheal intubation was required for airway preservation and EV naloxone was administered at $0.2 \mathrm{mg} / \mathrm{kg}$.

The condition was rapidly controlled and respiratory efforts resumed associate with awakening and extubation of the patient.

The patient was taken to the anesthetic recovery room and discharged after the intensive clinical observation period and reaching hemodynamic stability.

\section{DISCUSSION:}

The syndrome known as chest wall rigidity, chest tightness and breathing difficulties can occur during anesthetic induction with opioids and has been reported since 1953.

In the case at hand, since the opioids used, i.e., subarachnoid sufentanil and EV fentanyl, are highly liposoluble, their actions were leveraged and triggered this syndrome.

Because of that, the anesthesiologist must be always alert to identify the symdromeand provide management and treatment in the most accurate and effective manner.

\section{LEARNING POINTS:}

The anesthesiologist must be always alert to identify the symdrome and provide management and treatment in the most accurate and effective manner.

The anticipation of possible complicating events as well as a good relationship with the surgical team are key factors for achieving a safe procedure. 